See discussions, stats, and author profiles for this publication at: https://www.researchgate.net/publication/300060485

\title{
Detailed studies and stabilization methods of volcanic rocky slopes in coastal areas, Canary Islands, Spain
}

Chapter · May 2010

DOI: $10.1201 / \mathrm{b} 10549-26$

CITATIONS

0

3 authors, including:

\section{A. Lomoschitz}

Universidad de Las Palmas de Gran Canaria

51 PUBLICATIONS 427 CITATIONS

SEE PROFILE
READS

32

Antonio Cilleros

Universidad de Las Palmas de Gran Canaria 7 PUBLICATIONS 82 CITATIONS

SEE PROFILE

Some of the authors of this publication are also working on these related projects:

Engineering Geology View project

Large landslides View project 


\title{
Detailed studies and stabilization methods of volcanic rocky slopes in coastal areas, Canary Islands, Spain
}

\author{
A. Lomoschitz \& A. Cilleros \\ Departmento de Ingenieria Civil, Universidad de Las Palmas de Gran Canaria, Spain \\ R. Garcia-Ferrera \\ JOFRAHESA, S.L., Las Palmas de Gran Canaria, Spain
}

\begin{abstract}
Natural relief on mountainous volcanic islands has deep ravines, steep rocky slopes and high coastal cliffs. Volcanic formations have very heterogeneous rocks and soils. Besides, civil and building works sometimes include high cuts on the terrain and, as a result, many urban areas have been affected by rock falls and landslides. We show two case studies of the Canary Islands: (1) Rock fall hazard study and stabilization methods on Los Teques slope, Mogán, Southern Gran Canaria Island, and (2) Geologicgeotechnical study for a footpath project in Morro Jable coastal cliff, Pájara, Southern Fuerteventura Island. We conclude that sometimes classic methods of rock masses characterization are ineffective, while detailed geological studies are the best way to define and evaluate unstable zones on the slopes and to design the most convenient stabilization methods.
\end{abstract}

\section{INTRODUCTION}

Volcanic areas present an outstanding variety of rock and soil materials in a relatively random pattern. This wide diversity is a direct consequence of the genesis of the material by a wide range of volcanic activity and external factors which control eruption dynamics, transport, emplacement and reworking of the material being generated (del Potro \& Hürlimann 2007).

Occasionally, simplified graphic profiles of volcanic formations have been used, showing an alternance of lava flows, of middle to high strength, and interbedded pyroclastic layers, of low strength (Serrano et al. 2008). Moreover, natural slopes of volcanic layers are variable and sometimes they have a conical spatial disposal (volcanic cones) around central points of eruption. Besides, other features have to be considered such as the existence of syngenetic cooling joints, which are previous to tectonic jointing (Blyth \& de Freitas 1984, Schmincke 2004) and the influence of the strata thickness on the bearing capacity of the terrain and the stability of slopes (Lomoschitz, 1996).

In recent years, many works have been done on the geotechnical characterization and behaviour of volcanic rocks. They are about four main topics: (a) geomechanical characterization of intact rocks, from massive lava flows to pyroclasts, which are of a variety of geochemical compositions and textures (Rodríguez-Losada et al. 2007a,b); (b) field and geomechanical classification of volcanic formations (e.g., González de Vallejo et al., 2007, del Potro \& Hürlimann 2007); (c) strength and deformability models to interpret the behaviour of volcanic rocks (Kwasniewsky 2002, Serrano et al. 2002, 2007) and (d) case studies of engineering projects and works (e.g., Erichsen 2002, Simic 2007).

In this chapter, two case studies of volcanic rock slopes in coastal areas are shown (Fig. 1), which

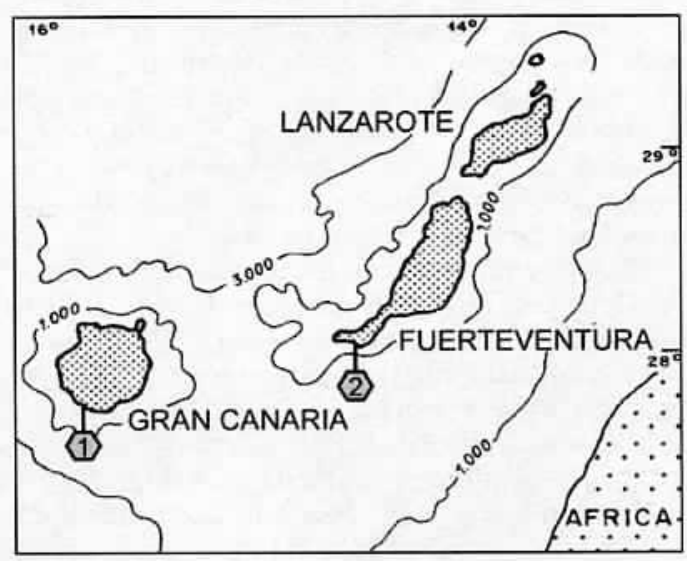

Figure 1. Map of the Eastern Canary Islands, $100 \mathrm{~km}$ off the northwest coast of Africa, and location (polygons 1 and 2) of the two study cases. 
were affected by a variety of rock falls and slides. Specific fieldwork methods were necessary for an effective characterization of rocks and to determine the most convenient stabilization techniques.

\section{CASE STUDIES}

\subsection{Los Teques apartments and slope, Southern Gran Canaria Is.}

In December 2005 a 11.6 metric ton rock block fell down on the back corridor of the apartments and the structure of the building was damaged. For some days, other smaller rock falls occurred. Afterwards, by means of a detailed geological study of the whole slope, $105 \mathrm{~m}$ long and $30 \mathrm{~m}$ high, 9 zones of medium to high risk were found out. In the study there were considered the strength and weathering of the rocks, potential rock fall mechanisms and trajectories, and the superficial and underground waters influence.

In addition, many specific solutions were proposed for the slope stabilization. Five building companies were consulted and some of them proposed more general and expensive stabilization methods than required. Finally, a variety of techniques were used (rock bolts, cable nets and dowels, concrete walls, shotcrete, cable belts, cable barriers, etc.) which were applied on specific areas.

Fieldwork was focused on three main targets: (1) Geological characterization of rocks and soils; (2) identification of unstable rock blocks and loose debris, and (3) definition of the best construction methods to retain or avoid potential rock falls, taking also in account the cost and effectiveness of each method.

The geological materials of the slope are of three main types: (a) acid volcanic agglomerate of fragments with ash and pumice which is a soft rock also affected by a fresh water spring; (b) 2 to 3 lava flow layers, which are ignimbrite of medium to high strength, and (c) some superficial scree and debris deposits. All rocks are of trachyte-rhyolite composition and they correspond to the Miocene magmatic cycle of Gran Canaria Is.

The volcanic agglomerate outcrops at the base of the slope, just behind the apartments, with a thickness of $10-15 \mathrm{~m}$. Its high slope angle $\left(70-80^{\circ}\right)$ and weathering had caused the undermining of the upper lava flow layers, which are $15-20 \mathrm{~m}$ thick. These layers had a number of unstable rock blocks with varied (wedge-, columnar-, cubic-) forms (Fig. 3).

When the unstable zones had been identified, one by one, a rock fall hazard map was done, considering three categories of risk: low, medium and high. Construction solutions were mainly focused on the stabilization of medium and high risk zones (Fig. 4).

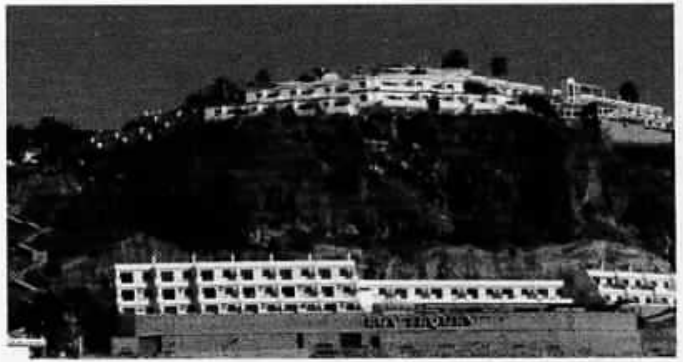

Figure 2. General view of Los Teques apartments and rocky slope in Southern Gran Canaria Island.

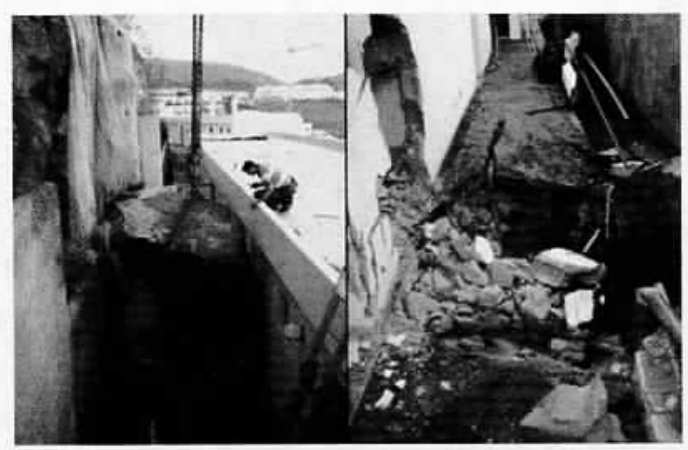

Figure 3. Removal of the 11.6 tons rock block that fell down at the back of the building. Damages caused by this rock fall.

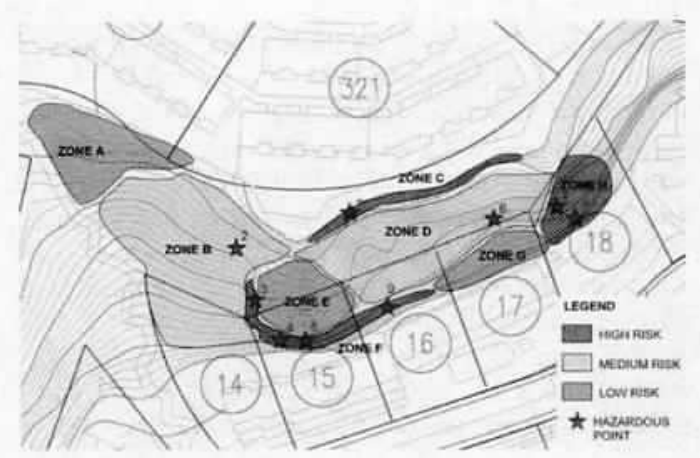

Figure 4. Risk map of Los Teques slope. Stabilization methods were focus on medium to high risk zones.

To evaluate the cost of construction works which were needed for the slope stabilization five building companies were consulted and some of them proposed more general and expensive stabilization methods than required. Finally, a variety of techniques were used (Fig. 5): 


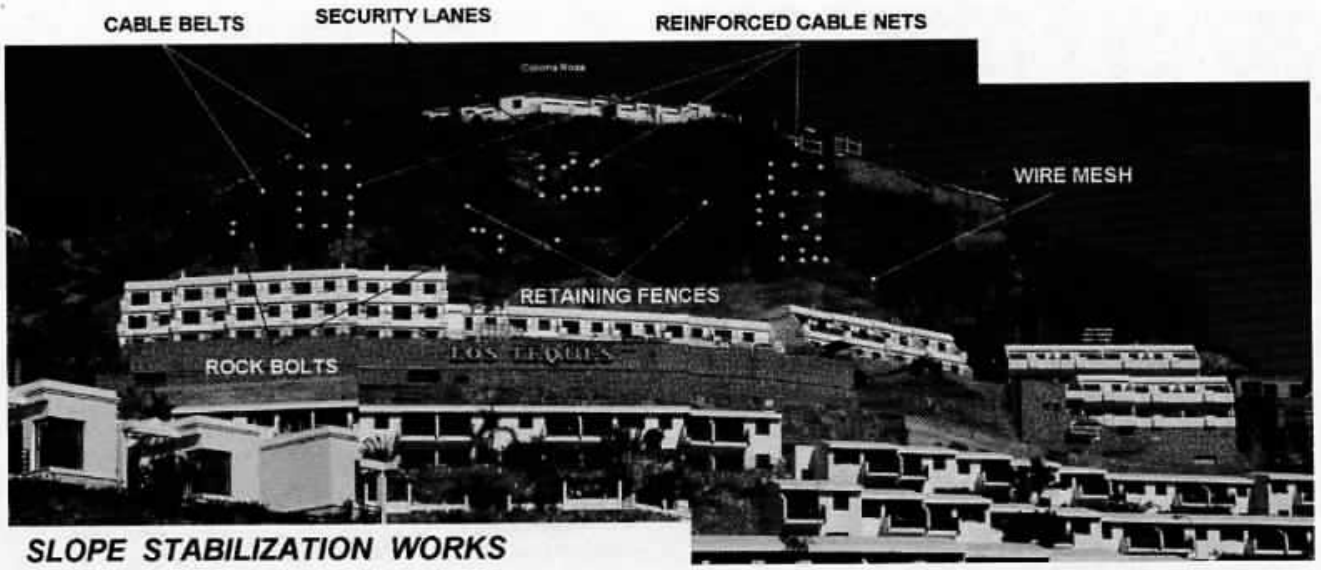

Figure 5. Stabilization methods used on Los Teques slope.

- Removal of loose stones and debris $\left(450 \mathrm{~m}^{2}\right)$.

- Concrete buttress to support rock above cavities $\left(18 \mathrm{~m}^{2}\right)$.

- 20 drain holes to reduce water pressure within slope.

- Wire mesh hung on vertical face of slope $\left(260 \mathrm{~m}^{2}\right)$.

- Reinforced cable net and rock bolts on unstable rock blocks $\left(180 \mathrm{~m}^{2}\right)$.

- Small fences ( $1 \mathrm{~m}$ high) to retain canalized debris flows ( 2 fences of $15 \mathrm{~m}$ ).

- Cable belts around semi-unstable rock columns (3 zones).

- Tensioned rock bolts in rock blocks (10 units).

The final cost of the stabilization works was $€ 45,000$, less than a half of the budget cost of other more extensive and general solutions.

\subsection{Morro Jable cliff and footpath, Southern Fuerteventura Is.}

In 2006 a project for a coast footpath, $450 \mathrm{~m}$ long, was done. It would connect Morro Jable harbour and El Matorral beach, located in a main tourist area at Southern Fuerteventura Island. The path had to be designed on a narrow strip of land, along a rocky cliff $30 \mathrm{~m}$ high, with a lot of caverns, landslide and rock-fall zones and very heterogeneous volcanic formations (Fig. 6).

About 40 percent of the footpath would be supported by the natural terrain and the remaining 60 percent by a metal structure of piles and girders. A detailed geological and geotechnical study was needed for an adequate development of the project, because of the irregular morphology of the shore and the geomechanical features of the cliff. In the study there were included: (a) a geomorphologic

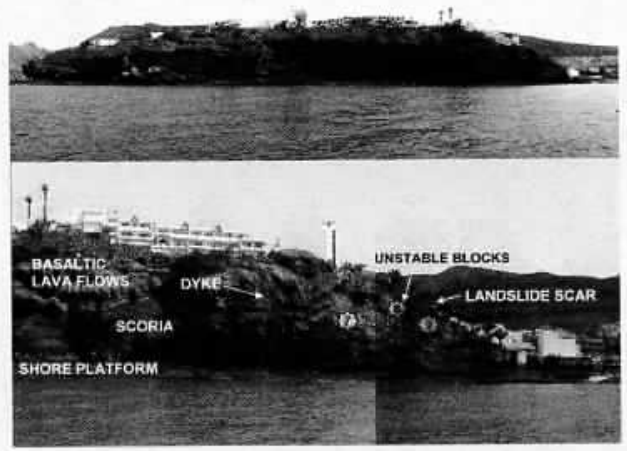

Figure 6. General view of Morro Jable Cliff in Fuerteventura Island. Differentiation of geological materials on the slope.

map of the shore, indicating cavern and slide zones, rocky platforms, gravel and sand beaches; (b) a geological section along the cliff with a description of the volcanic layers and dykes; (c) the location of unstable rocky wedges and blocks; (d) volume measurement of caverns and caves at the base of the slope; (e) proposal of protection methods against the coastal erosion and stabilization techniques for the unstable zones; and (f) evaluation of the soil or rock bearing capacity for each of the foundation points.

The geological study has been focussed on the two parts of the zone: the tidal shore platform and the rocky cliff.

The tidal shore platform is composed of basalt rocks, corresponding to intrusive bodies and tephra agglomerates, small patches of carbonate beachrock and boulder and gravel beaches. 


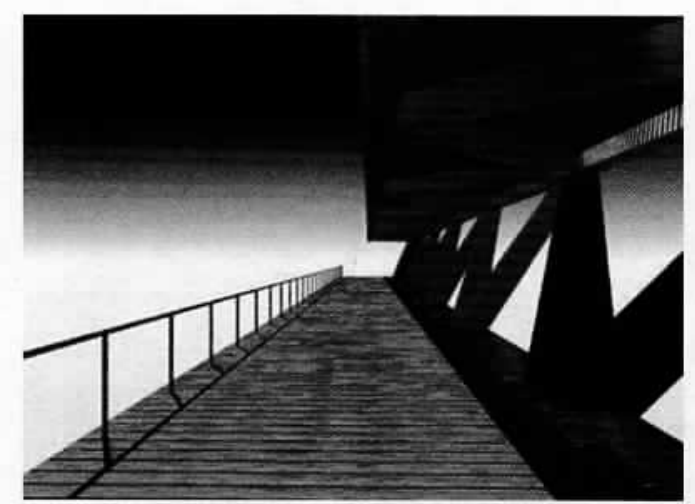

Figure 7. Designed footpath structure.

The cliff includes three groups of materials: (a) Irregular layers of basaltic breccia of scoria and lapilli in the first one third part of the cliff wall; (b) basaltic lava flows, massive and extensive, which compound the upper two thirds of the cliff, and (c) a number of volcanic dikes, of basaltic and trachytic composition, that intrude the country rock. All rocks correspond to the Miocene volcanic edifice of Jandia.

It was done a geological and geomechanical description of every material, which included an evaluation of the bearing capacity at each support point of the structure (Fig. 7).

However, along the shore there are many hazardous zones for the project of the coast footpath:

-2 zones affected by large landslides: the first is $60 \mathrm{~m}$ long and $20 \mathrm{~m}$ high and has had big rock topple and fall movements, and the second is $40 \mathrm{~m}$ long and $18 \mathrm{~m}$ high and has produced a huge debris flow deposit on the shore platform.

- 7 potentially unstable zones at different points of the cliff wall.

-9 zones with caverns and caves at the base of the cliff.

- 3 zones on the cliff with a high degree of erodibility.

Every zone has been studied individually, having searched a building solution for each one. For instance: concrete buttresses and stone walls to support rock above caverns and caves; rock removal at some places; concrete injection inside open joints; tensioned rock bolts; reinforced cable net and bolts on unstable rock wedges and columns, etc.

\section{CONCLUSION}

In many occasions, slopes on volcanic formations do not follow homogeneous or simple patterns (in terms of geometry, thickness, jointing, weathering, etc.) In these cases, classic methods for rock masses characterization are ineffective, and detailed geological studies are the best way to define and evaluate unstable zones on the slopes and to design the most convenient stabilization methods.

\section{REFERENCES}

Blyth, F.G.H. \& de Freitas, M.H. 1984. A Geology for Engineers. London: Edgard Arnold.

del Potro, R. \& Hürlimann, M. 2007. Strength of volcanic rock masses in edifice instability: Insights from Teide, Tenerife. In A.M. Malheiro \& J.C. Nunes (eds), Volcanic Rocks: 175-184. London: Taylor \& Francis Group.

Erichsen, C. 2002. Geotechnical models or classification of the bedrock as a basis for the design and for the construction of rock structures: 15-26. In C. Dinis da Gama and L. Ribeiro e Sousa (eds), Workshop on volcanic rocks, Eurock 2002, Funchal, 27 November, 2002.

González de Vallejo, L.I., Hijazo, T., Ferrer, M. \& Seisdedos, J. 2007. Geomechanical characterization of volcanic materials in Tenerife. In A.M. Malheiro \& J.C. Nunes (eds), Volcanic Rocks: 21-28. London: Taylor \& Francis Group.

Kwasniewsky 2002. A note on the triaxial strenght on volcanic rocks: $27-36$. In C. Dinis da Gama and L. Ribeiro e Sousa (eds), Workshop on volcanic rocks, Eurock 2002, Funchal, 27 November, 2002.

Lomoschitz, A. 1996. Caracterización geotécnica del terreno, con ejemplos de Gran Canaria y Tenerife. Escuela Técnica Superior de Arquitectura, Universidad de Las Palmas de Gran Canaria.

Rodriguez-Losada, J.A. Hernández-Gutiérrez, L.E. Olalla, C. Perucho, A. Serrano, A. \& del Potro, R. et al. 2007a. The volcanic rocks of the Canary Islands. Geotechnical properties. In A.M. Malheiro \& J.C. Nunes (eds), Volcanic Rocks: 53-58. London: Taylor \& Francis Group.

Rodríguez-Losada, J.A., Hernández-Gutiérrez, L.E. Lomoschitz, A. 2007b. Geotechnical features of the welded ignimbrites of the Canary Islands. In A.M. Malheiro \& J.C. Nunes (eds), Volcanic Rocks: 29-34. London: Taylor \& Francis Group.

Schmincke, H-U. 2004. Volcanism. Berlin: Springer.

Serrano, A., Olalla, C. \& Perucho, A. 2002. Evaluation of non-linear strength laws for volcanic agglomerates: 53 60. In C. Dinis da Gama and L. Ribeiro e Sousa (eds), Workshop on volcanic rocks, EUROCK 2002, Funchal, 27 November, 2002.

Serrano, A., Olalla, C. \& Perucho, A. 2008. Estabilidad de taludes en materiales heterogéneos. II Jornadas Canarias de Geotecnia, Tacoronte, Tenerife, 21-23 May 2008.

Serrano, A., Olalla, C., Perucho, A. \& HernándezGutiérrez, L.E. 2007. Strength and deformability of low density pyroclasts: $35-44$. In C. Dinis da Gama and L. Ribeiro e Sousa (eds), Workshop on volcanic rocks, EUROCK 2002, Funchal, 27 November, 2002.

Simic, D. 2007. Foundation of the "Los Tilos" arch bridge in La Palma Island: 113-122. In C. Dinis da Gama and L. Ribeiro e Sousa (eds), Workshop on volcanic rocks, EUROCK 2002, Funchal, 27 November, 2002. 